\title{
IMPLEMENTASI ANTENA WAJANBOLIC SEBAGAI PENERIMA SIGNAL HOTSPOT
}

\author{
Eka Wahyudi ${ }^{1)}$, Irwan Susanto ${ }^{2)}$, Andhy Triono ${ }^{3)}$ \\ ${ }^{1), 2), 3)}$ Program Studi D3 Teknik Telekomunikasi AKATEL Sandhy Putra Purwokerto
}

\begin{abstract}
ABSTRAK
Perkembangan teknologi informasi dan telekomunikasi telah memadu menjadi satu. Teknologi informasi banyak berkaitan dengan konten sementara teknologi komunikasi banyak berkaitan dengan infrastruktur. Sistem komunikasi merupakan salah satu kebutuhan manusia yang paling dasar dan sebuah sistem selalu membutuhkan medium sebagai pembawa sinyal. Maka dari itu dibutuhkan alat pendukung sebagai penghubung pembawa sinyal dalam sebuah jaringan, salah satunya yaitu teknologi wireless. Salah satu bagian dalam teknologi wireless ini yaitu antena. Dari berbagai bentuk antena, antena wajanbolic merupakan antena yang praktis dan sederhana untuk diimplementasikan. Fungsi dari antena wajanbolic ini yaitu untuk mengumpulkan sinyal yang dipancarkan oleh acces point. Komponen utama dalam membuat wajanbolic adalah USB wireless adapter. Dalam implementasi wajanbolic tersebut, diperoleh jarak maksimal jangkauan acces point yang mampu diterima sekitar 150 meter dimana lintasan sinyal dalam keadaan clear of sight (CLOS).
\end{abstract}

Kata kunci : wireless, acces point, wajanbolic, USB wireless adapter.

\section{A. PENDAhULUAN}

Dalam era globalisasi perkembangan teknologi informasi dan telekomunikasi memadu menjadi satu. Teknologi informasi banyak berkaitan dengan konten sementara teknologi komunikasi banyak berkaitan dengan infrastruktur, penyatuan ini mampu memberikan layanan komunikasi dan informasi bagi manusia.

Jaringan internet sebagai salah satu implementasi teknologi informasikomunikasi (infokom) mampu memberikan layanan komunikasi data. Dengan layanan ini masyarakat dapat bertukar informasi melalui pengiriman data, pemanfaatan internet saat ini sedang digemari oleh masyarakat.

Salah satu opsi akses yang ekonomis adalah dengan berlangganan internet bersama kemudian didistribusikan kebeberapa client. Untuk lebih meringankan biaya distribusi jaringan internet salah satunya dengan pengadaan antena yang dapat dibangun dari berbagai jenis alat dan bahan yang biasa dijumpai atau sudah familiar pada kehidupan sehari-hari.

Bahwa saat ini telah banyak dikenal teknologi sederhana berkaitan dengan penggunaan antena yang dapat menjadi opsi yang murah yaitu salah satunya antena wajanbolic. Melihat kondisi geografis yang luas maka untuk mengakses suatu jaringan dipergunakan teknologi wireless. Untuk itu perlu dilakukan percobaan dalam pembuatan antena wajanbolic dan bagaimana pemanfaatannya.

\section{Jaringan Komputer}

Jaringan komputer merupakan gabungan antara teknologi komputer dan teknologi komunikasi. Gabungan teknologi melahirkan pengolahan data yang dapat didistribusikan, mencakup pemakaian database, software aplikasi dan peralatan hardware secara bersamaan, untuk membantu proses otomatisasi perkantoran dan peningkatan ke arah efisiensi kerja. Adapun Tipe jaringan terdiri dari 2 type yaitu: 
- Jaringan Client Server

- Jaringan Peer to Peer

\section{Prinsip Dasar Jaringan}

Berdasarkan lingkup atau luas daerah kerja secara geografis, jaringan komputer dapat dibedakan ke dalam beberapa macam, yaitu:

- Local Area Network (LAN)

- Metropolitan Area Network (MAN)

- Wide Area Network (WAN)

- Interconnection Network (Internet)

Dari jenis jaringan tersebut dapat dibedakan lagi berdasarkan topologi/bentuk jaringannya. Topologi Jaringan adalah gambaran secara fisik dari pola hubungan antara komponen-komponen jaringan, yang meliputi server, workstation, hub dan pengkabelannnya. Terdapat tiga macam topologi jaringan umum digunakan, yaitu Bus, Star dan Ring.

\section{Komponen Hardware}

Untuk membangun jaringan dibutuhkan beberapa elemen dasar yang memungkinkan antar komputer dapat saling berkomunikasi. Elemen dasar (komponen) meliputi perangkat komputer (hardware) seperti: Server, Workstation, Network Interface Card (NIC), dan Kabel, sedangkan komponen software meliputi : PC operating system, sistem operasi jaringan, protocol jaringan.

\section{Jaringan Wireless}

Wireless local area network (WLAN) adalah sistem komunikasi data yang fleksibel yang dapat diimplementasikan sebagai perpanjangan atau pun sebagai alternatif pengganti untuk jaringan kabel $L A N$. Dengan menggunakan teknologi frekuensi radio, wireless $L A N$ mengirim dan menerima data melalui media udara, dengan meminimalisasi kebutuhan akan sambungan kabel. Dengan begitu, wireless LAN telah dapat mengkombinasikan antara konektivitas data dengan mobilitas user.

a. Perangkat Wireless

1) Access Point

Access point berfungsi sebagai titik akses yang menghubungkan komputer-komputer ke dalam sebuah jaringan. Access point fungsinya sama dengan $H U B$ pada jaringan dengan menggunakan kabel. Access point biasanya dilengkapi dengan antena dan port RJ45.

Access point merupakan sebuah perangkat penghubung antara jaringan dengan wireless, acces point akan bertugas mengubah data melewati di media kabel menjadi sinyal-sinyal radio yang dapat ditangkap oleh perangkat wireless. Acces point akan menjadi gerbang bagi jaringan wireless untuk dapat berkomunikasi dengan dunia luar maupun dengan antar sesama perangkat wireless di dalamnya.

Acces Point biasanya memiliki sistem antena untuk mentransmisikan sinyalsinyalnya. Sistem antenanya bermacammacam. Penggunaan acces point yang banyak tentu akan meningkatkan kapasitas pengguna dan juga jarak coverage jaringan wireless. Selain itu juga dapat menciptakan sebuah system roaming WLAN. Maksudnya para 
pengguna dapat bergerak dengan bebas tanpa terputus koneksinya karena sinyal-sinyal komunikasinya dapat dilayani oleh beberapa acces point yang berbeda.

Access point sangat dibutuhkan jika ingin membuat sebuah infrastruktur jaringan wireless. Dengan menggunakan acces point, maka sebuah jaringan komunikasi akan terbentuk tidak hanya dua atau tiga perangkat saja yang dapat berkomunikasi tetapi cukup banyak yang dapat saling berbicara dengan perantara sinyal radio ini. Selain itu dengan menggunakan acces point, jaringan kabel dengan wireless juga dapat berhubungan sehingga komunikasi jaringan menjadi lebih lebar.

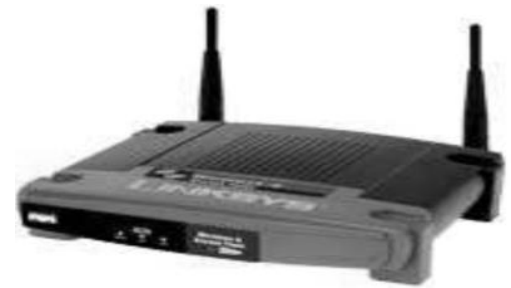

Gambar 1. Acces Point

\section{Wireless LAN Card}

Pada jaringan wireless ada Wireless LAN Card. Card ini biasa terpasang pada slot PCI komputer. Card ini berfungsi untuk menghubungkan komputer ke dalam jaringan. Ada berbagai tipe Wireless LAN Card yang dapat dipakai, baik di dalam ruangan dengan kemampuan jarak tertentu hingga yang mempunyai jangkauan yang jauh. Wireless LAN Card dengan kemampuan yang jauh biasanya dilengkapi dengan antena luar.

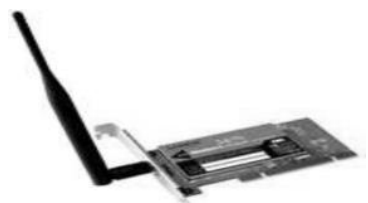

Gambar 2. Wireless LAN Card

\section{Wireless PCMCIA}

Alat ini biasa dipakai pada laptop atau notebook, alat ini seperti halnya NIC, hanya saja dengan bentuk yang berbeda dan lebih tipis karena akan dipasang pada perangkat yang kecil (laptop). Saat ini notebook sudah banyak yang dilengkapi dengan fasilitas wireless,

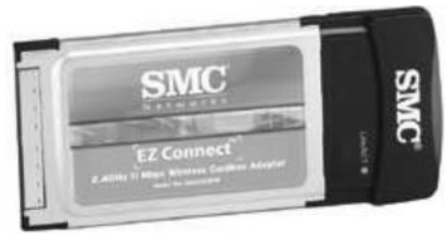

Gambar 3. Wireless PCMCIA

\section{Wireless USB}

Universal Serial Bus (USB) banyak dijumpai pada port komputer sekarang ini. wireless USB ini akan dipasang pada port $U S B$ di komputer. Ada 2 jenis Wireless $U S B$ yang ada di pasaran yaitu Wireless USB Stick dan Adapter. Jangkauan dari yang bertipe Adapter lebih luas dibandingkan dengan yang Stick.
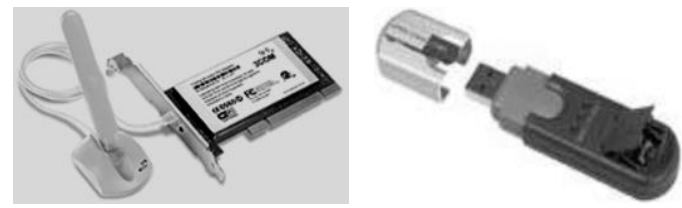

Gambar 4. Wireless USB Adapter

\section{Wireless Local Area Network (WLAN)}

Jaringan komputer yang terhubung melalui tanpa kabel. Local Area Network dari komputer dan peralatan lainnya yang berkomunikasi lewat sinyal radio atau gelombang cahaya. Sistem ini berguna apabila penyambungan lewat koneksi kabel atau serat optik cukup mahal atau untuk aplikasi koneksi bergerak. Teknologi komunikasi data dengan tidak menggunakan kabel untuk 
menghubungkan antara klien dan server. Secara umum teknologi Wireless LAN hampir sama dengan teknologi jaringan komputer yang menggunakan kabel (Wire LAN atau Local Area Network). Teknologi Wireless $L A N$ ada yang menggunakan frekuensi radio untuk mengirim dan menerima data yang tentunya mengurangi kebutuhan atau ketergantungan hubungan melalui kabel. Akibatnya pengguna mempunyai mobilitas atau fleksibilitas yang tinggi dan tidak tergantung pada suatu tempat atau lokasi. Teknologi juga memungkinkan untuk membentuk jaringan komputer yang mungkin tidak Wireless LAN dapat dijangkau oleh jaringan komputer yang menggunakan kabel.

Kelebihan Wireless LAN antara lain yaitu:

a) Mobility

b) Installation Speed and Simplicity

c) Installation Flexibility

d) Reduced Cost-of-Ownership

e) Scalability

\section{Cara Kerja Wireless LAN}

Wireless LAN menggunakan electromagnetic airwaves (radio atau infrared) untuk menukarkan informasi dari satu titik ke titik lainnya tanpa harus tergantung pada sambungan secara fisik. Gelombang radio biasa digunakan sebagai pembawa karena dapat dengan mudah mengirimkan daya ke penerima. Data ditransmikan dengan cara ditumpangkan pada gelombang pembawa sehingga dapat diextract pada ujung penerima. Data ini umumnya digunakan sebagai pemodulasi dari pembawa oleh sinyal informasi yang sedang ditransmisikan. Begitu datanya sudah dimodulasikan pada gelombag radio pembawa, sinyal radio akan menduduki lebih dari satu frekuensi, hal ini terjadi karena frekuensi atau bit rate dari informasi yang memodulasi ditambahkan pada sinyal carrier.

Multiple radio carrier dapat ada dalam suatu ruang dalam waktu yang bersamaan tanpa terjadi interferensi satu sama lain jika gelombang radio yang ditransmisikan berbeda frekuensinya. Untuk mengextract data, radio penerimanya diatur dalam satu frekuensi dan menolak frekuensi-frekuensi lain. Pada konfigurasi wireless LAN tertentu, transmitter/receiver (transceiver) device, biasa disebut access point, terhubung pada jaringan kabel dari lokasi yang fixed menggunakan kabel standar. Sebuah access point dapat mensupport sejumlah group kecil dari user dan dapat dipakai dalam jarak antara seratus sampai beberapa ratus kaki. Access point (atau antena yang terhubung pada access point) biasanya diletakkan pada tempat yang tinggi tapi dapat juga diletakkan dimana saja untuk mendapatkan cakupan yang dikehendaki. End user access wireless LAN menggunakan wireless-LAN adapters, biasa terdapat pada $P C$ card pada notebook atau palmtop computer, atau sebagai card dalam desktop computer, atau terintegrasi dalam hand-held computer.

\section{Antena}

Antena adalah suatu piranti yang digunakan untuk menambahkan daya pancar dari sinyal analog serta merambatkan dan menerima gelombang radio atau elektromagnetik. Pemancaran merupakan satu 
proses perpindahan gelombang radio atau elektromagnetik dari saluran transmisi ke ruang bebas melalui antena pemancar. Sedangkan penerimaan adalah satu proses penerimaan gelombang radio atau elektromagnetik dari ruang bebas melalui antena penerima. Karena merupakan perangkat perantara antara saluran transmisi dan udara, maka antena harus mempunyai sifat yang sesuai (match) dengan saluran pencatunya. Macam - macam Antena antara lain yaitu:

a. Antena Directional (Antena pengarah)

Antena directional merupakan antena yang memancarkan daya ke arah tertentu. Jenis antena ini digunakan pada sisi client dan mempunyai gain yang sangat tinggi yang diarahkan ke Access Point.

b. Antena Omnidirectional

Antena Omnidirectional adalah antena yang memancarkan daya ke segala arah, dan bentuk pola radiasinya digambarkan seperti bentuk donat (doughnut) dengan pusat berimpit. Antena ini ada dalam kenyataan, dan dalam pengukuran sering digunakan sebagai pembanding terhadap antena yang lebih kompleks. Biasanya antena jenis ini digunakan pada Access Point. Antena jenis ini mempunyai pola radiasi $360^{\circ}$.

\section{Antena Wajanbolic}

Dalam matematika, parabola adalah irisan kerucut yang berbentuk kurva yang dihasilkan oleh perpotongan menyilang yang sejajar terhadap permukaan kerucut. Direktris adalah garis sumbu simetri pada parabola terhadap titik fokus. Sedangkan fokus dari parabola adalah letak suatu titik dimana jarak antara titik sembarang pada garis parabola $\mathrm{M}(\mathrm{x}, \mathrm{y})$ ke fokus adalah sama dengan jarak antara $\mathrm{M}(\mathrm{x}, \mathrm{y})$ ke direktris $\mathrm{D}(\mathrm{x}, 0)$.

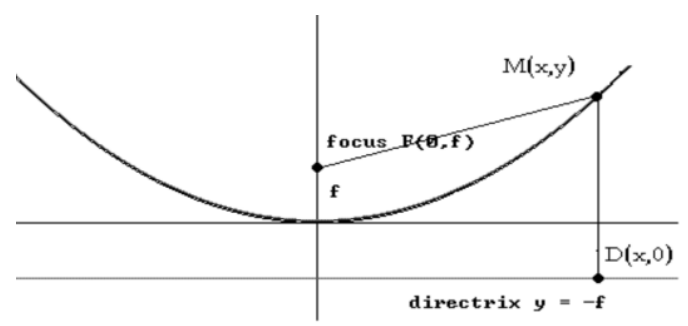

Gambar 5. Fokus dan direktris

Dari pengertian diatas diketahui bahwa nilai dari jarak titik $\mathrm{F}$ (fokus) ke titik $\mathrm{M}$ dan jarak dari titik M ke titik D (direktris) adalah sama, sehingga dapat dihasilkan persamaan:

$$
\sqrt{(x-0)^{2}+(y-f)^{2}}=\sqrt{(x-x)^{2}+(y-(-f))^{2}}
$$

Karena pada persamaan diatas kedua sisi sama-sama mempunyai akar, maka dapat dieliminasi sehingga menghasilkan persamaan :

$$
\begin{aligned}
& x^{2}+y^{2}+f^{2}-2 y f=y^{2}+f^{2}+2 y f \\
& x^{2}+y^{2}-y^{2}+f^{2}-f^{2}=2 y f+2 y f \\
& x^{2}=4 y f \\
& y=\frac{x^{2}}{4 f}
\end{aligned}
$$

Gambar 6. terlihat diameter dari parabola (D) dan kedalaman parabola (d). Dari dua parameter tersebut maka dapat dihitung nilai/letak dari titik fokus parabola. 


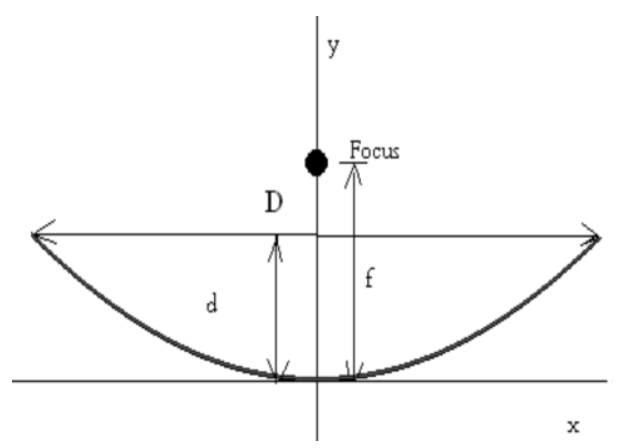

Gambar 6. Penghitungan nilai fokus

$$
\begin{aligned}
& d=\frac{D^{2}}{16 f} \\
& 16 f=\frac{D^{2}}{d} \\
& f=\frac{\frac{D^{2}}{d}}{\frac{16}{1}} \\
& f=\frac{D^{2}}{d} x \frac{1}{16} \\
& f=\frac{D^{2}}{16 d}
\end{aligned}
$$

Dari persamaan diatas dapat diperhatikan bahwa semakin besar nilai diameter dari suatu parabola $(D)$ dan semakin kecil nilai kedalaman $(d)$ suatu parabola, maka nilai fokusnya akan menjadi semakin besar.

Pada dasarnya antena wajanbolic hampir sama dengan antena parabola. Letak perbedaannya hanya pada reflektor. Jika pada antena parabola biasa reflektor adalah dish yang didesain khusus agar dapat memantulkan sinyal dengan sebagaimana mestinya, maka jika pada antena wajanbolic, reflektor berupa wajan yang sering dijumpai.

\section{Reflektor}

Antena wajan bolic menggunakan reflektor dari wajan yang berbahan alumunium karena bahan alumunium secara umum merupakan bahan yang ringan bila dibandingkan dengan bahan logam lainnya. Hal ini tentu merupakan sebuah keuntungan bila akan mengimplementasikan antena wajanbolic karena walaupun mempunyai dimensi besar, bobot dari antena tersebut akan tetap lebih ringan jika dibandingkan dengan menggunakan bahan logam lain.

Penggunaan reflektor dimaksudkan untuk mendapatkan penguatan (gain) yang lebih besar bila dibandingkan hanya menggunakan wireless USB adapter biasa atau hanya menggunakan antena kaleng (waveguide). Karena setiap gelombang yang datang dari fokus akan dipantulkan oleh permukaan reflektor dengan arah yang sejajar dengan sumbu atau sebaliknya.

\section{B. METODOLOGI PENELITIAN}

a. Bahan

1) Wajan

Langkah pengukuran wajan adalah:

a) Diamater wajan,

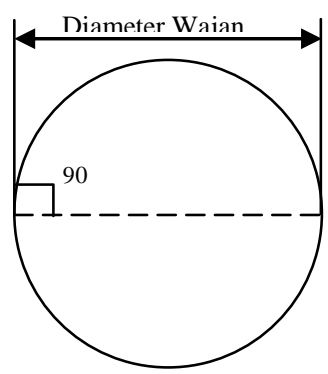

Gambar 7. Diameter Wajan

b) Kedalaman wajan

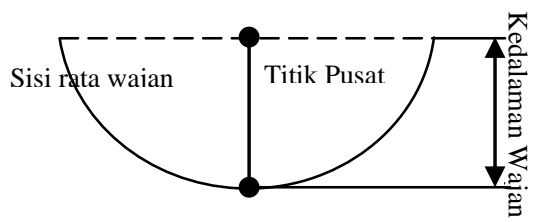

Gambar 8. Kasadaajajan Kan Wajan 
2) Pipa Paralon

Pipa paralon yang digunakan mempunyai diameter 3 inch. Pipa paralon dibutuhkan untuk tempat penangkapan gelombang yang dipantulkan oleh wajan, pada pipa paralon ini akan ditempatkan wireless USB dan sebagian permukaannya akan dilapisi dengan aluminium foil.

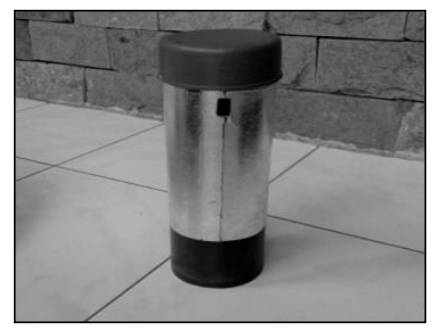

Gambar 9. Pipa paralon

3) Wireless USB (Universal Serial Bus)

Wireless USB dibutuhkan untuk menangkap sinyal gelombang yang sudah terkumpul untuk disalurkan ke PC/komputer.

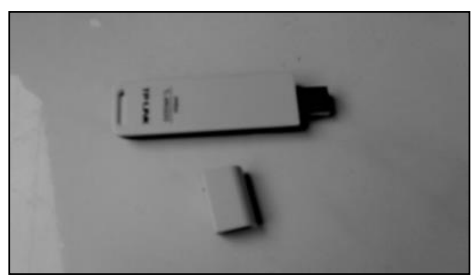

Gambar 10. Wireless USB

4) Kabel Wireless USB

Kabel Wireless USB dibutuhkan untuk penghubung dari Wireless USB ke PC/komputer.

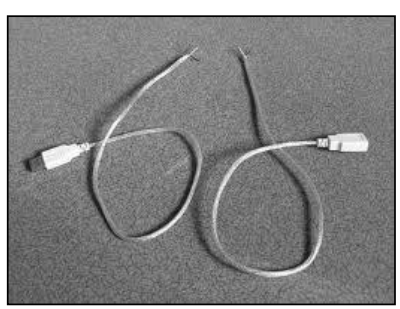

Gambar 11. Kabel Wireless USB

5) Kabel UTP (Unshielded Twisted Pair)
Kabel UTP dibutuhkan untuk perpanjangan kabel $U S B$.

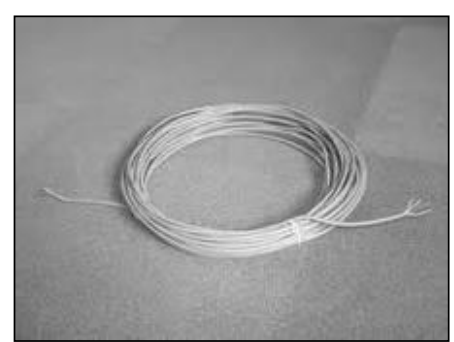

Gambar 12. Kabel UTP

6) Dop paralon

Dop Paralon yang digunakan mempunyai diameter 3 inchi sesuai dengan pipa paralon yang digunakan. Dop Paralon dibutuhkan untuk dinding penempel pipa paralon ke wajan dan penutup ujung paralon.

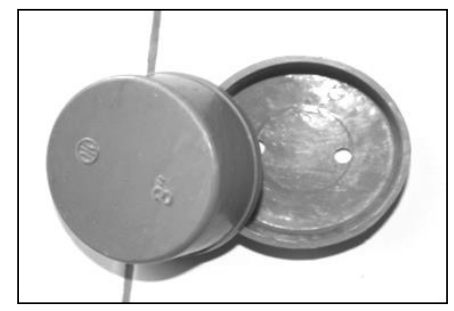

Gambar 13. Dop Paralon

7) Aluminium Foil

Aluminium Foil dibutuhkan untuk melapisi pipa paralon dan salah satu dop paralon agar mampu berfungsi sebagai konduktor.

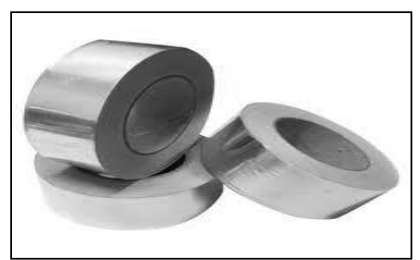

Gambar 14. Aluminium Foil

b. Sketsa Jaringan Wireless menggunakan Antena Wajanbolic.

Sketsa Jaringan Wireless menggunakan Antena Wajanbolic tampak seperti Gambar 15. 


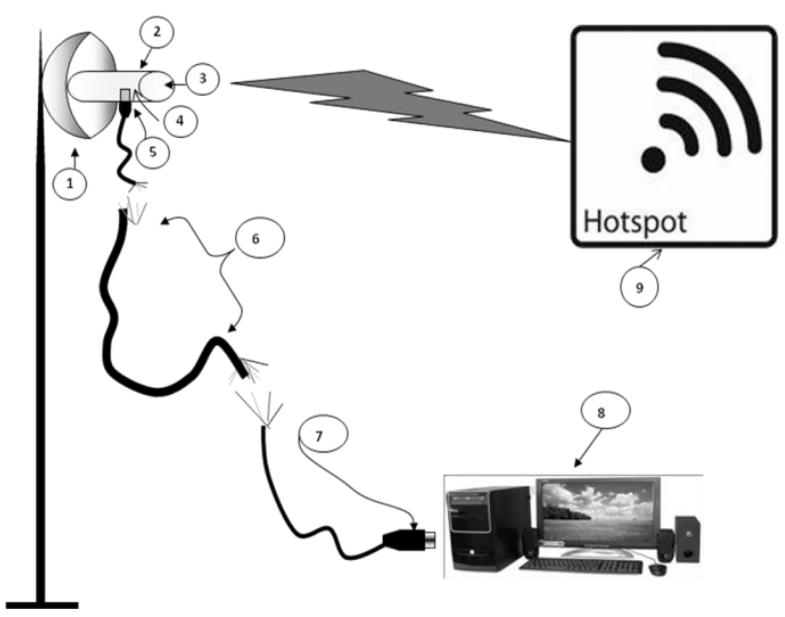

Gambar 15. Sketsa Jaringan Wireless Antena

\section{Wajanbolic}

Keterangan Gambar :

1. Wajanbolic

2. Pipa Paralon

3. Penutup Pipa/Dop Paralon

4. Wireless USB

5. Kabel $U S B$

6. Kabel UTP

7. USB Wireless Female

8. Personal Komputer

\section{HASIL DAN PEMBAHASAN}

Pengujian dilakukan terutama terhadap koneksi jaringan. Pengujian ini dimaksudkan untuk membuktikan bahwa antena wajanbolic dapat digunakan sebagai salah satu opsi antena. Selanjutnya untuk mengetahui sejauh mana kemampuan antena wajanbolic mampu menjadi salah satu pilihan sebagai antena, maka dilakukan pula pengujian terhadap kecepatan akses. Adapun langkah-langkah pengujian alat adalah sebagai berikut :

1. Proses Pengujian Koneksi Jaringan

Pengujian alat dilakukan untuk mengetahui apakah antena wajanbolic mampu menangkap sinyal hotspot, hal ini diwakili dengan terkoneksi jaringan ke internet.

Langkah Pengujian :

Pengujian dilakukan menggunakan $P C$. Dalam pengujian ini menggunakan browser Mozilla Firefox. Adapun situs yang dituju www.google.com. Hasil pengujian akses menuju situs www.google.com yang dilakukan pada hari rabu tanggal 06 oktober 2010 pukul 16.00 WIB tampak seperti Gambar 16.

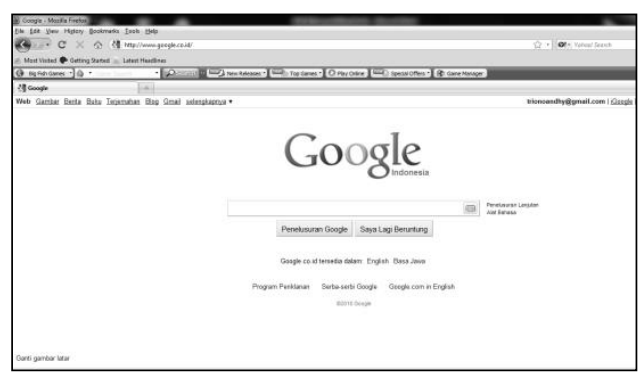

Gambar 16. Pengujian Koneksi Jaringan

Untuk lebih membuktikan bahwa sinyal mampu ditangkap oleh antena wajanbolic maka dilakukan pengujian sinyal menggunakan software netstumbler. Hasil pengujian sinyal dilakukan pada kondisi cuaca terang/tidak hujan, cuaca hujan, dan cuaca hujan lebat/deras. Pengujian dilakukan pada pagi, siang dan malam hari.

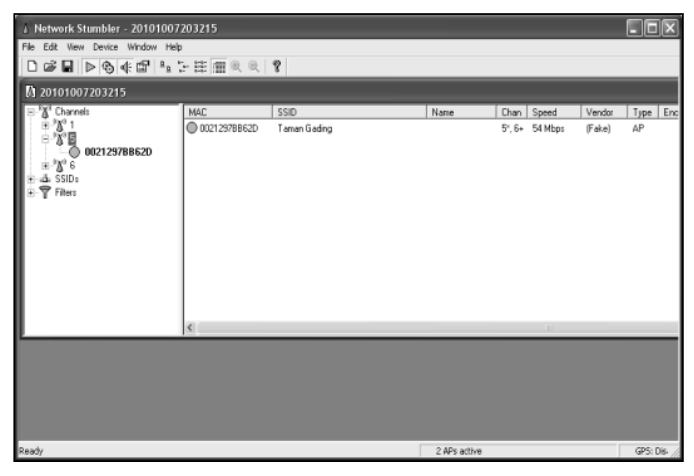

Gambar 17. Pengujian Sinyal menggunakan software netstumbler

a. Hasil pengujian sinyal pada cuaca terang/tidak hujan tampak pada Gambar 18 berikut ini : 


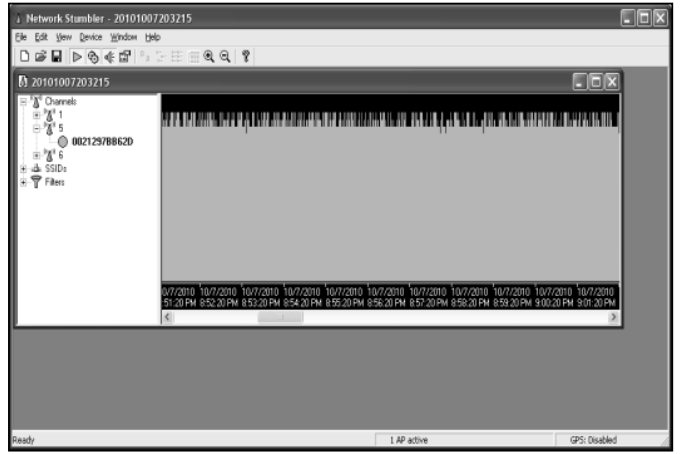

Gambar 18. Pengujian sinyal pada cuaca terang/tidak hujan.

b. Hasil pengujian sinyal pada cuaca hujan tampak pada Gambar 19 berikut ini :

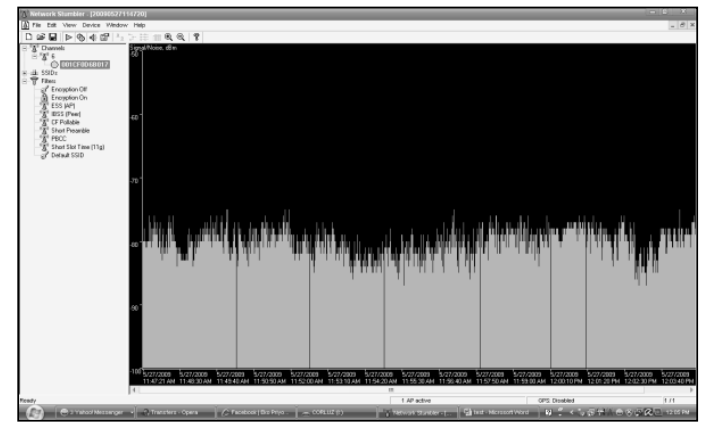

Gambar 19. Pengujian sinyal pada cuaca hujan

c. Hasil pengujian sinyal pada cuaca hujan lebat/deras tampak pada Gambar 20.

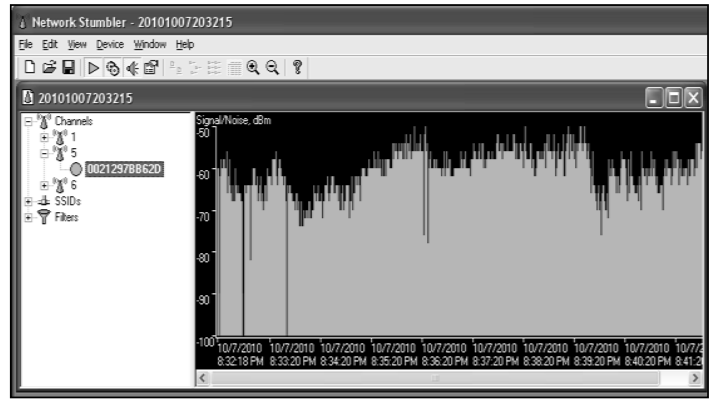

Gambar 20. Pengujian sinyal pada cuaca hujan lebat/deras.

\section{Hasil Pengujian Koneksi Jaringan}

Hasil pengukuran/test bandwith yang diterima oleh Wireless USB ditunjukkan selama proses pengujian. Perbandingan hasil pengukuran besarnya bandwith tanpa menggunakan antena wajanbolic dan menggunakan antena wajanbolic. Diuji pengukuran diarahkan ke server Speedtest Semarang.

Tabel 1. Hasil Pengujian Kecepatan Akses

\begin{tabular}{|c|l|c|c|}
\hline No & \multicolumn{1}{|c|}{ Pengujian } & $\begin{array}{c}\text { Bandwith } \\
\text { (Mbps) }\end{array}$ & $\begin{array}{c}\text { Upload } \\
\text { (Mbps) }\end{array}$ \\
\hline 1 & $\begin{array}{l}\text { Pengujian akses menggunakan wireless } \\
\text { USB (Wireless USB langsung } \\
\text { dimasukan ke port USB pada PC) tanpa } \\
\text { antena wajanbolic dan kabel extender } \\
\text { dari client ke hotspot/acces point }\end{array}$ & 0,35 & 0,07 \\
\hline 2 & $\begin{array}{l}\text { Pengujian akses menggunakan wireless } \\
\text { USB dan kabel extender, tanpa } \\
\text { menggunakan antena wajanbolic }\end{array}$ & 0,37 & 0,07 \\
\hline 3 & $\begin{array}{l}\text { Pengujian akses menggunakan wireless } \\
\text { USB, kabel extender, dan menggunakan } \\
\text { antena wajanbolic }\end{array}$ & 0,40 & 0,09 \\
\hline 4 & $\begin{array}{l}\text { Pengujian dengan sudut pointing } 45^{0} \\
\text { dari arah acces point }\end{array}$ & 0,32 & 0,08 \\
\hline 5 & $\begin{array}{l}\text { Pengujian dengan sudut pointing 90 } \\
\text { dari arah acces point }\end{array}$ & 0,22 & 0,05 \\
\hline
\end{tabular}

3. Kelebihan dan Kekurangan Antena

Dari Hasil Test/Pengujian didapatkan kelebihan dan kekurangan antena antara lain :

1) Kelebihan dibanding tanpa antena

Tanpa antena tidak membutuhkan banyak peralatan/bahan dan instalasinya mudah serta cepat guna.

2) Kekurangan yang masih ada

Bahan dan material pembuatan antena yang masih kurang serta penggunaan peralatan yang masih belum diperhatikan kepresisiannya, sehingga hasil yang diperoleh kurang sesuai dengan perhitungan.

\section{PENUTUP}

Setelah dilaksanakan experiment pembuatan dan pemanfaatan antena wajanbolic ini, beberapa hal yang menjadi kesimpulan yaitu:

1. Dalam pembuatan antena wajanbolic peralatan utama yang dibutuhkan adalah Wajan, Wireless USB, kabel extender 
(sambungan kabel USB dan kabel UTP), aluminium foil , pipa paralon dan dop paralon.

2. Di dalam instalasi koneksi antena wajanbolic ke $P C$ langkah instalasi yang dilakukan hanya menginstall koneksi wireless USB ke PC.

3. Kelebihan dibanding tanpa antena tidak memerlukan banyak peralatan/bahan dan instalasinya mudah serta cepat guna, sedangkan Kekurangan yang masih ada yaitu meliputi bahan dan material pembuatan antena yang masih kurang serta penggunaan peralatan yang masih belum diperhatikan kepresisiannya, sehingga hasil yang diperoleh kurang sesuai dengan perhitungan.

4. Untuk pengembangan pemanfaatan antena dapat dilanjutkan dengan studi perbandingan antara antena wajanbolic dengan antena yang lain seperti antena kaleng. Dan perbandingan bahan antara aluminium dengan bahan non aluminium.

\section{E. Daftar Pustaka}

1. Adiyanto, Molin., 2008, Proyek Akhir Pembuatan Antena Wajanbolic - Politeknik Elektronika Negeri Surabaya, Surabaya.

2. Sopandi, Dede., 2005, Instalasi dan Konfigurasi Jaringan Komputer, Informatika Bandung.

3. Nana, Suarna., 2007, Petunjuk Teoritis Pengantar LAN (Local Area Network), Yrama Widya, Bandung,

4. 05 Agustus 2010, Pengenalan

Wireless

$L A N$

(wifi).http://dudik.blogdetik.com/2008/05/

31/wlan-wireless-local-area networks/.

5 . 01 Okt 2010, Pengertian MAN

(Metropolitan Area Network). http://muhsub.blogspot.com/2009/03/pengerti an-man-metropolitan-area.html.

6. Purwanto, Eddy., 12 September 2010, Sejarah Internet,

http://www.google.co.id/\#hl=id\&source=hp\& biw $=981 \&$ bih=520\&q=http $\% 3 \mathrm{~A} \% 2 \mathrm{~F} \% 2 \mathrm{Flitb}$ ang.depkes.go.id\%2Ftik\%2Fmedia\%2FPenga ntar_WWW.doc\&aq=f\&aqi $=\& a q l=\& o q=\& g s$ _rfai $=\& f p=230 \mathrm{ca} 2 \mathrm{ae} 376 \mathrm{fd} 1 \mathrm{c} 8$

7. ., 08 Agustus 2010, Cara Cepat

Akses Internet.

http://community.siutao.com/showthread.ph $\mathrm{p} ? \mathrm{t}=4516$.

8. 08 Agustus 2010,.Pembuatan Antena Wajanbolic.

http://opensource.telkomspeedy.com/wiki/ index.php/KeRmIT:_Pembuatan_Wajanb olic.

9. 09 Juli 2010, Teknik USB Extender.

http://opensource.telkomspeedy.com/wiki/ index.php/Teknik_USB_extender.

10 . 01 Oktober 2010, Denah

Lokasi Perumahan Taman Gading Cilacap. http://wikimapia.org/.

11. 10 Oktober 2010, Test

Bandwith. http://www.speedtest.net.

12. Susanto, Irwan., 2004, Panduan Penulisan Tugas Akhir - Akademi Teknik Telekomunikasi Sandhy Putra Purwokerto. Purwokerto. 